\title{
Self-assembly mechanism of Ni nanowires prepared with an external magnetic field
}

\author{
Xiaoyu Li, Hu Wang, Kenan Xie, Qin Long, Xuefei Lai and Li Liao*§
}

\author{
Full Research Paper \\ Address: \\ School of Chemical Engineering, Sichuan University, Chengdu \\ 610065, PR China \\ Email: \\ Li Liao* - liaolis@scu.edu.cn \\ * Corresponding author \\ § Tel: +86-28-85464466; Fax: +86-28-85403397 \\ Keywords: \\ chemical reduction; external magnetic field; Ni nanoparticles; $\mathrm{Ni}$ \\ nanowires; self-assembly mechanism
}

Beilstein J. Nanotechnol. 2015, 6, 2123-2128.

doi:10.3762/bjnano.6.217

Received: 15 July 2015

Accepted: 28 October 2015

Published: 09 November 2015

Associate Editor: P. Ziemann

(c) 2015 Li et al; licensee Beilstein-Institut.

License and terms: see end of document.

\begin{abstract}
Nickel nanowires with a mean diameter of about $95 \mathrm{~nm}$ and lengths of up to $26 \mu \mathrm{m}$ were prepared by a chemical reduction method in aqueous solution under an external magnetic field. The self-assembly mechanism was investigated in detail. The results indicate that the self-assembly process of Ni nanowires consists of three stages: nucleation and growth, ordered alignment and selfassembly, and deposition on the surface and gaps between the nickel particles. The self-assembly phenomenon occurs only when nickel particles grow to a size of about $60 \mathrm{~nm}$ in the reaction system. This critical size, which is proposed for the first time, is very important to comprehend the self-assembly mechanism of Ni nanowires prepared with an external magnetic field.
\end{abstract}

\section{Introduction}

For the past decades, ferromagnetic (e.g., Fe, Co, Ni) nanowires have raised considerable attention due to their application prospects in magnetic, optoelectronic, electronic, sensor and electrochemical devices [1-6]. In particular, Ni nanowires have been the focus of intense research due to their easy preparation compared with iron and cobalt nanowires. There are several reported routes for the preparation of Ni nanowires including template-based electrodeposition [7-10], block copolymer lithography [11], and wet chemical reduction [12]. Among these methods, template-based electrodeposition is the most widely used to prepare Ni nanowires as highly-ordered and size- controlled nanowires can be obtained with this method. However, additional steps such as preparing and removing the templates are required for this method.

Recently, a self-assembly method employing a magnetic field to prepare ferromagnetic nanowires has been extensively studied because of its simplicity and effectiveness. For example, Wang et al. $[13,14]$ synthesized nickel and cobalt nanowires using a gamma irradiation technique under an external magnetic field. Li et al. [15] synthesized nickel chains under a weak magnetic field by hydrazine reduction in ethylene glycol. Smooth Ni 
nanowires were prepared by $\mathrm{Hu}$ et al. [16] under a stronger magnetic field. Soumare et al. [17] synthesized nickel nanowires with a diameter of $250 \mathrm{~nm}$ and a length of several microns via a chemical reduction method with an external magnetic field of $1.4 \mathrm{~T}$. Liu et al. [18] prepared Ni nanowires with a diameter of $50 \mathrm{~nm}$ via a hydrazine reduction route under external magnetic field assistance.

However, it should be noted that more attention has been paid to the exploration of preparation systems using the magneticassisted method for the shape control of the resulting nanowires under an external magnetic field, as opposed to the selfassembly mechanism of this method. The team of Makoto Kawamori [19-21] proposed a possible mechanism of selfassembly speculated from the morphology of nickel and cobalt nanowires. Meng et al. [22] proposed a similar mechanism. However, no related experiments were designed to prove their proposed self-assembly mechanism. Herein, Ni nanowires are synthesized in aqueous solution by a template-free method combined with chemical reduction and the application of an external magnetic field. Based on a previous study $[23,24]$, this paper focuses on the morphology change during the reaction in order to place the self-assembly mechanism into perspective. Surprisingly, nickel nanowires cannot be formed if the diameter of the nickel nanoparticles does not reach a critical size.

\section{Experimental}

All chemicals were of analytical grade without further purification. All reaction solutions were located between two parallel neodymium magnets $\left(60 \times 30 \mathrm{~mm}^{2}\right)$ separated $150 \mathrm{~mm}$ apart. The magnetic intensity inside the reaction solution was approximately $15 \mathrm{mT}$, which was measured by a magnetometer. In a typical synthesis, $0.10 \mathrm{~g}$ of $\mathrm{NiSO}_{4} \cdot 6 \mathrm{H}_{2} \mathrm{O}$ and $0.11 \mathrm{~g}$ of $\mathrm{C}_{6} \mathrm{H}_{5} \mathrm{Na}_{3} \mathrm{O}_{7} \cdot 2 \mathrm{H}_{2} \mathrm{O}$ were dispersed in $60 \mathrm{~mL}$ of distilled water in a $100 \mathrm{~mL}$ PTFE beaker. After the temperature of the reaction solution reached $80^{\circ} \mathrm{C}, 0.25 \mathrm{~g}$ of $\mathrm{NaOH}$ was added to the solution under strong stirring until it was completely dissolved. Then, $2 \mathrm{~mL}$ of $80 \mathrm{wt} \% \mathrm{~N}_{2} \mathrm{H}_{4} \cdot \mathrm{H}_{2} \mathrm{O}$ and $50 \mu \mathrm{L}$ alkaline sodium borohydride solution $\left(3 \mathrm{~g}\right.$ of $\mathrm{NaBH}_{4}$ and $1 \mathrm{~g}$ of $\mathrm{NaOH}$ were dissolved in $20 \mathrm{~mL}$ of distilled water) were added into the solution with agitation, and the time was recorded immediately and was considered as the starting time of the reaction. The end time of the reaction was defined as when the solution became transparent. Finally, the resulting products were collected, rinsed three times with distilled water and ethanol. In order to investigate the self-assembly mechanism, a series of experiments similar to the above were accomplished, and the only difference was that these reaction liquids were poured into $400 \mathrm{~mL}$ of cooled, distilled water after the reaction progressed for $30 \mathrm{~s}$, $60 \mathrm{~s}, 120 \mathrm{~s}, 180 \mathrm{~s}, 200 \mathrm{~s}, 220 \mathrm{~s}, 240 \mathrm{~s}$ and $300 \mathrm{~s}$. These products were rinsed after being stored for $12 \mathrm{~h}$.
The size and morphology of the products were observed using a field emission scanning electron microscope (FESEM, JHOL, $\mathrm{S}-450)$. The composition and crystallographic properties of the products were characterized by X-ray diffraction (XRD, Philips, $\mathrm{X}^{\prime}$ pert) in the range from $10-80^{\circ}$ with a scanning rate of $0.02 \%$. Transmission electron microscopy (TEM) images were obtained using a JEOL JEM-100CX TEM.

\section{Results}

In Figure 1, the corresponding XRD pattern for the Ni samples is shown. Three characteristic peaks for $\mathrm{Ni}\left(2 \theta=44.51^{\circ}\right.$, $51.85^{\circ}$, and $76.37^{\circ}$, corresponding to Miller indices (111), (200), and (220)) were found and no impurity peaks were detected. These results indicate that the as-prepared $\mathrm{Ni}$ nanowires consisted of pure face-centered-cubic (fcc) $\mathrm{Ni}$ (according to powder diffraction file JCPDS 01-1260). It is generally known that nickel is easily oxidized, but peaks of $\mathrm{NiO}$ were not observed due to the additional $\mathrm{N}_{2}$ produced during the reaction, which protects the Ni nanowires from oxidization. The crystallite size of the Ni nanowires $(16 \mathrm{~nm})$ calculated from the (111) fcc Ni peaks by Scherrer's equation is smaller than the apparent wire diameter $(\approx 95 \mathrm{~nm})$. This indicates that the as-prepared Ni nanowires are polycrystals.

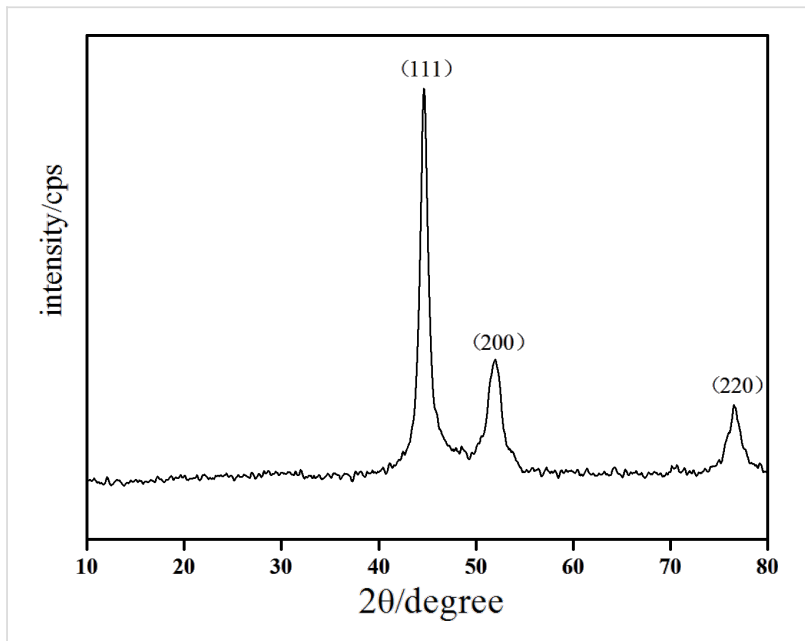

Figure 1: XRD pattern of nickel nanowires.

The SEM and TEM images displaying the morphology of the final Ni samples are shown in Figure 2, which indicate that the Ni samples exhibit a chain-like configuration. This implies that the as-prepared Ni nanowires with a diameter of about $95 \mathrm{~nm}$ and a length of about $26 \mu \mathrm{m}$ are composed of spherical-like particles that are connected with each other and form straight chains. Notably, the Ni samples remain chain-like after ultrasonication for $30 \mathrm{~min}$, which implies that the $\mathrm{Ni}$ particles grow together and do not simply aggregate. Moreover, the Ni samples likely have a polydomain structure because the single-domain 


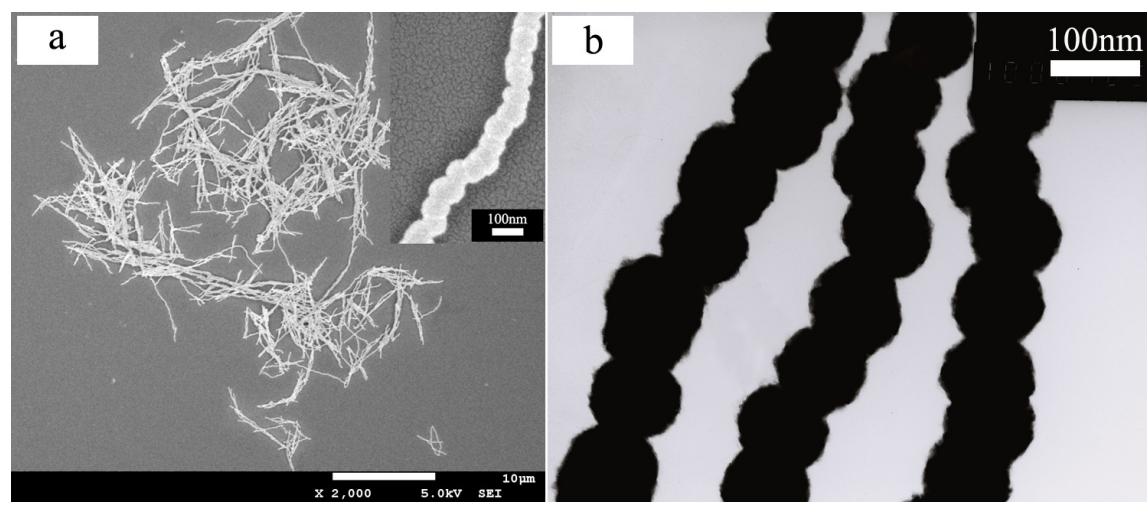

Figure 2: SEM (a) and TEM (b) images of the final Ni samples.

diameter for $\mathrm{Ni}$ is about $55 \mathrm{~nm}$ with a spherical particle shape [25].

Figure 3 shows the morphology change of Ni nanowires during the reaction. Obviously, only spherical particles can be seen at $30 \mathrm{~s}$ (Figure 3a), $60 \mathrm{~s}$ (Figure 3b), and $120 \mathrm{~s}$ (Figure 3c), while chain-like wires can be seen at $240 \mathrm{~s}$ (Figure 3d) although a number of individual particles can also been seen in this graph. Only chains of particles are observed at $300 \mathrm{~s}$ (Figure 3e) and $600 \mathrm{~s}$ (Figure 3f). It can be inferred that as-prepared $\mathrm{Ni}$ nanowires are comprised of connected, single nickel nanoparticles. It is worth noting that the self-assembly phenomenon arises only when nickel particles have grown to a critical size of about $60 \mathrm{~nm}$ in the reaction system. Interestingly, the particle diameters in Figure 3a (about 60-125 nm) and Figure 3b (about $70-95 \mathrm{~nm}$ ) are larger than those in Figure 3c (about 40-55 nm) and Figure $3 \mathrm{~d}$ (about $55-65 \mathrm{~nm}$ ). It is known that the total interfacial area of a system must decrease with the time to reach thermodynamic equilibrium by a diffusional mass transfer process from high interfacial curvature regions to low interfacial curvature regions. The interfacial area reduction process is generally called coarsening or Ostwald ripening, which is briefly illustrated in Figure 4 [26-29]. Therefore, this interesting phenomenon may be attributed to Ostwald ripening: while the size of particles is uniformly distributed at $120 \mathrm{~s}$, the difference in size of particles at $30 \mathrm{~s}$ and $60 \mathrm{~s}$ is larger thus smaller particles dissolve and transfer their mass to the larger particles. The difference in the size of particles at $60 \mathrm{~s}$ is smaller than that at $30 \mathrm{~s}$.

\section{Discussion}

In the present system, the product produced by the reduction reaction of $\mathrm{NaBH}_{4}$ was induced into nucleation and formed insoluble crystals in the reaction solution. The overall nickel reduction by hydrazine in aqueous solution can be described as follows:

$$
2 \mathrm{Ni}(\mathrm{II})+\mathrm{N}_{2} \mathrm{H}_{4}+4 \mathrm{OH}^{-} \rightarrow 2 \mathrm{Ni}+\mathrm{N}_{2}+4 \mathrm{H}_{2} \mathrm{O}
$$

where $\mathrm{Ni}(\mathrm{II})$ represents all $\mathrm{Ni}$ (II) species in the solution such as $\mathrm{Ni}^{2+}$, nickel-citrate complexes, $\mathrm{Ni}(\mathrm{OH})_{2},\left[\mathrm{Ni}\left(\mathrm{N}_{2} \mathrm{H}_{4}\right)_{3}\right]^{2+}$, $\left[\mathrm{Ni}\left(\mathrm{N}_{2} \mathrm{H}_{4}\right)_{2}\right]^{2+}$ and $\left[\mathrm{Ni}\left(\mathrm{NH}_{3}\right)_{6}\right]^{2+}[30]$. The above reaction can be separated into an anode reaction $\left(\mathrm{N}_{2} \mathrm{H}_{4}\right.$ oxidation) and a cathode reaction (Ni deposition).

The possible self-assembly mechanism shown in Figure 5 was deduced from the morphology change of Ni nanowires during the reaction and can be divided into three stages. Firstly, small $\mathrm{Ni}$ nanoparticles are generated in the reaction solution by the initiation reaction of $\mathrm{NaBH}_{4}$, regardless of the presence of the external magnetic field. Then, these nanoparticles become larger and larger as the reduction reaction of $\mathrm{N}_{2} \mathrm{H}_{4}$ proceeds. These steps, corresponding to Figure $5 \mathrm{a}$ and Figure 5b, respectively, can be called the first stage. Nanoparticles are mainly affected by Brownian motion and electrostatic repulsive force in this stage because the magnetic interaction between nanoparticles is too weak to overcome the molecular resistance of the solvent since the dipole magnetic moment of a nanoparticle is proportional to its volume [31]. Similarly, the interaction between the nanoparticle and the external magnetic field is also negligible, thus the motion of Ni nanoparticles cannot be influenced by the external magnetic field. As the reaction proceeds, the diameter of the Ni nanoparticles reaches a critical size where the dipole magnetic moments of the nanoparticles are aligned with the external magnetic field direction, as shown in Figure 5c. Meanwhile, Ni nanoparticles are aligned along the magnetic induction lines (Figure 5d). A nickel particle chain (Figure 5e) is formed since the magnetic interaction between nanoparticles becomes stronger as the size of Ni nanoparticles increases, which results in an enhancement of the van der Walls forces between Ni particles. That is the second stage of the selfassembly mechanism. The critical Ni nanoparticle size has an 


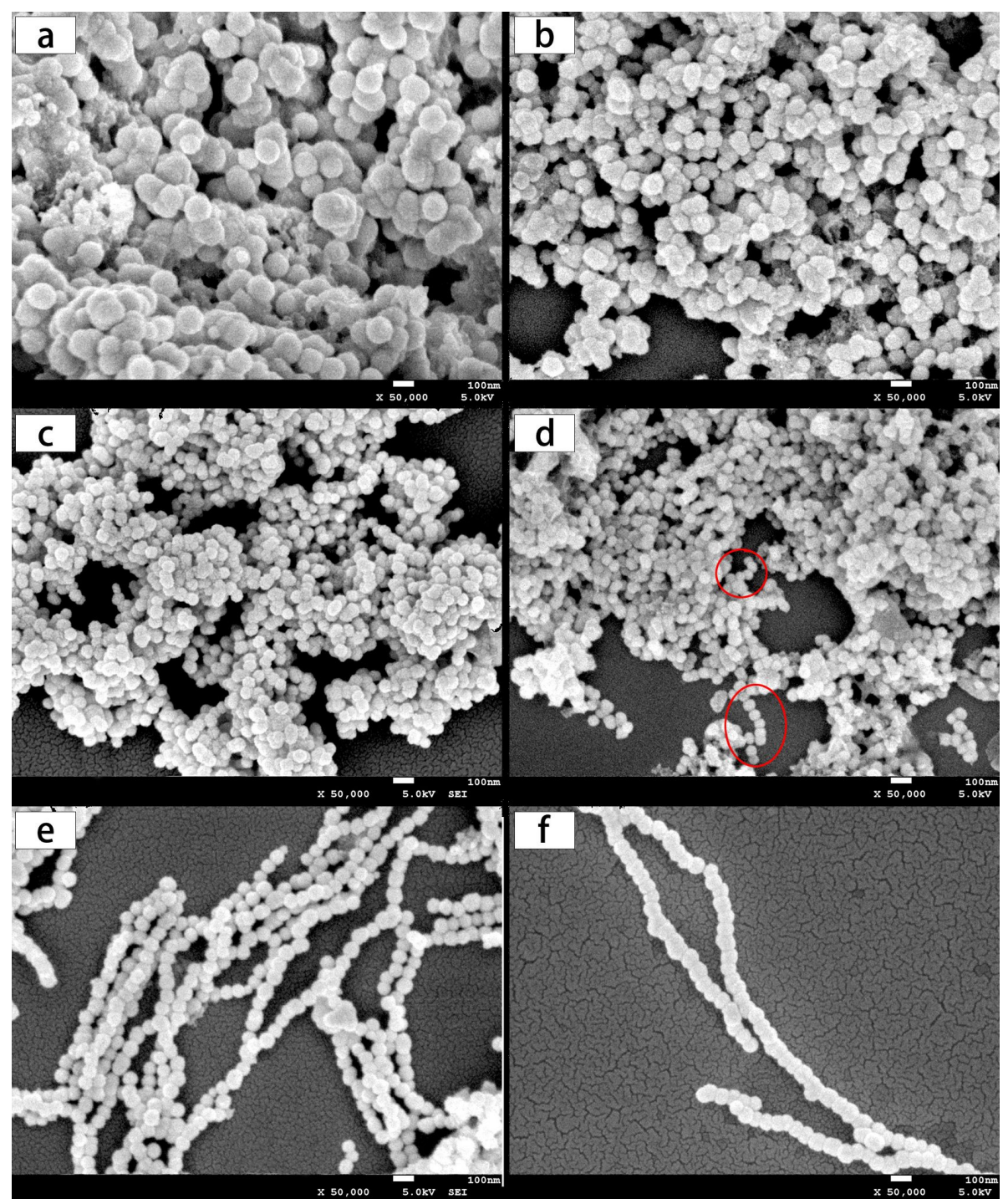

Figure 3: SEM micrographs of products prepared after the reaction proceeded for $30 \mathrm{~s}(\mathrm{a}), 60 \mathrm{~s}$ (b), $120 \mathrm{~s}$ (c), $240 \mathrm{~s}$ (d), $300 \mathrm{~s}(\mathrm{e})$, and $600 \mathrm{~s}$ (f).

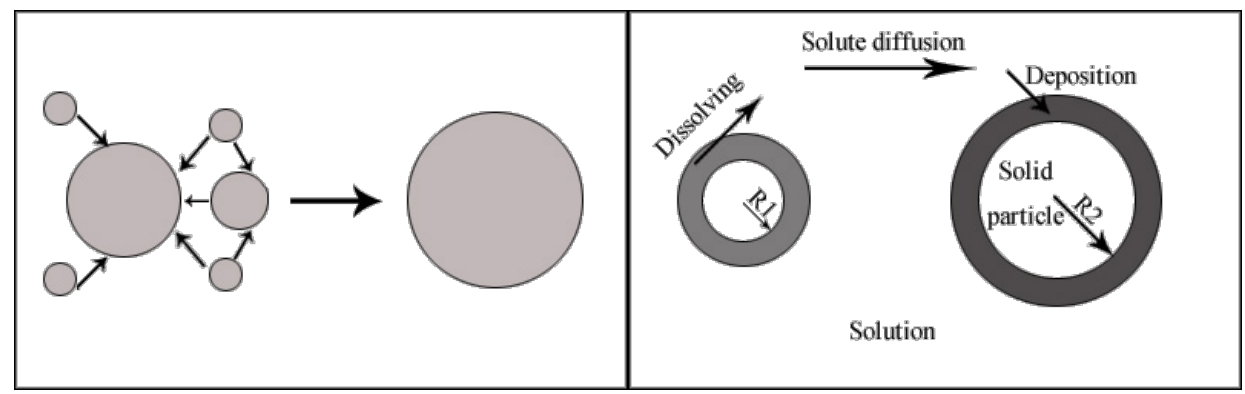

Figure 4: Ostwald ripening: (a) the process of Ostwald ripening involves small particles being engulfed by larger particles; (b) process diagram of Ostwald ripening.

especially important meaning since it is the inflection point between $\mathrm{Ni}$ nanoparticles and $\mathrm{Ni}$ nanowires in the reaction system and is the key to the mechanism. It can be defined as the critical size of self-assembly. This is an inevitable consequence of various interaction forces such as magnetic interaction between magnetic dipoles, van der Walls forces, the molecular 


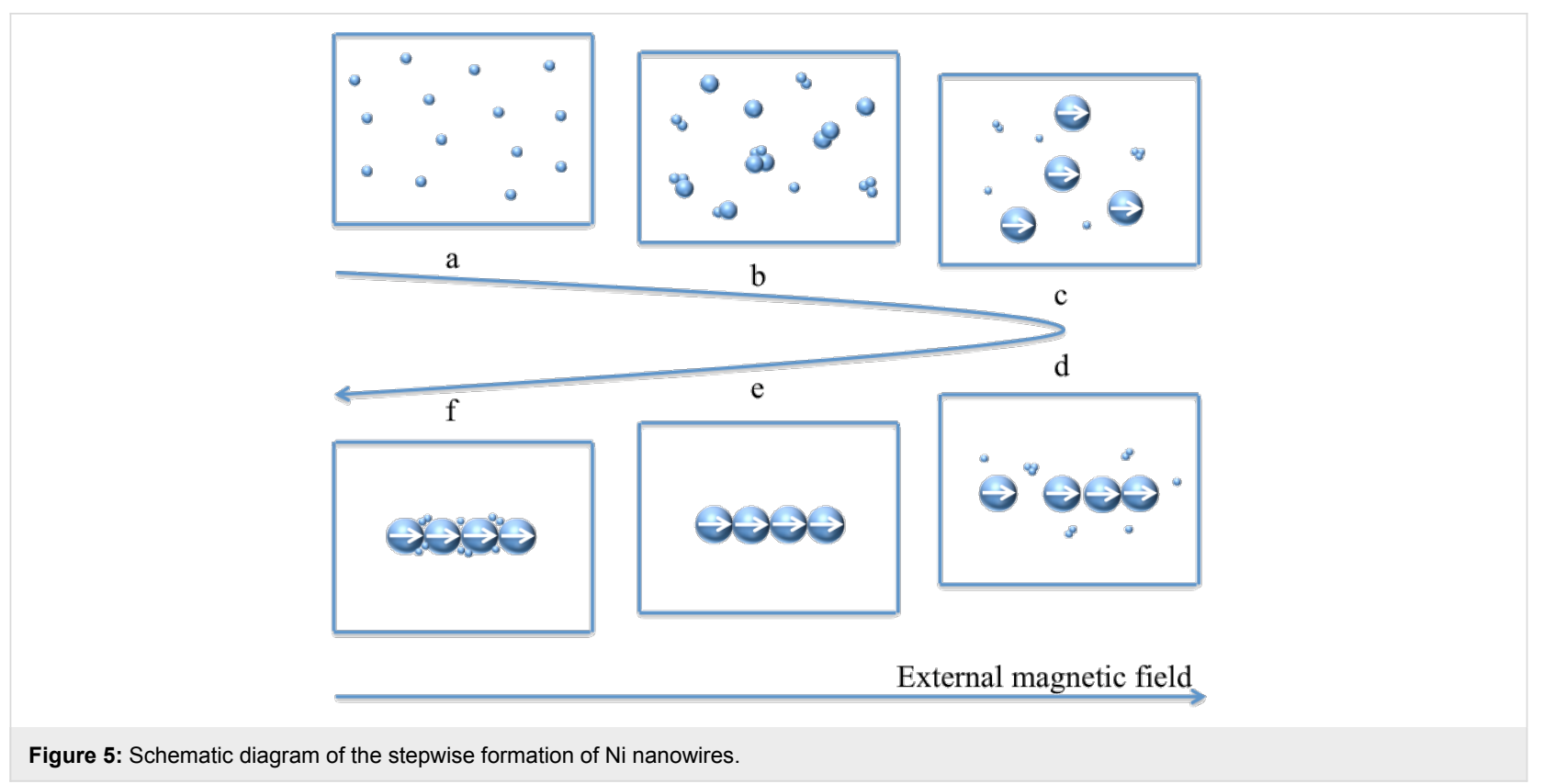

resistance of the solvent, Brownian motion and electrostatic repulsive forces. Therefore, the critical size of self-assembly is closely related to the magnetic field strength and temperature of the reaction system. In the third phase, $\mathrm{Ni}(\mathrm{II})$ preferentially deposits in the gaps between particles to decrease the interfacial energy, as shown in Figure 5f, which can be demonstrated by Figure $3 \mathrm{e}$ and Figure $3 \mathrm{f}$. Comparing the diameter of the nanowires in Figure 3e and Figure 3f, it is doubtless that Ni(II) deposits on the surface of the nickel nanowires as well.

Interestingly, magnetic nanoparticles can be first prepared and then aligned into one-dimensional chain-like structures in ferrofluids under a magnetic field [32-35]. The self-assembly behavior is similar to the second stage of the above selfassembly mechanism. Only chain-like nanowires can be prepared by this assembly method, while the above mechanism indicates that $\mathrm{Ni}$ nanoparticles, $\mathrm{Ni}$ nanowires with chain-like structure and Ni nanowires with smooth surfaces can all be prepared in the given reaction system as long as the reaction is terminated at different stages by cooling with a large amount of distilled water or liquid nitrogen. Of course, the reaction can conclude at different stages by adjusting the process conditions if the critical size of self-assembly is clear for the reaction system. This demonstrates that the critical size of self-assembly is of great significance in order to understand the self-assembly mechanism of Ni nanowires prepared under an external magnetic field.

\section{Conclusion}

Under an external magnetic field, polycrystalline nickel nanowires were synthesized by a chemical reduction method.
Further studies indicated that the self-assembly process involves three stages: nucleation and growth, ordered alignment and selfassembly, and the deposition on the surface and in the gaps between nickel particles. Particularly, this self-assembly phenomenon arises only when the diameter of the spherical nickel nanoparticle reaches a critical size, which is the key of the self-assembly mechanism of nickel nanowires. This critical size is also of great importance for preparing nickel nanomaterials (nanoparticles, nanochains and nanowires with a smooth surface) in an aqueous solution system under an external magnetic field.

\section{Acknowledgements}

Financial support by the National Natural Science Foundation of China (Grant No. 50904046) is gratefully acknowledged.

\section{References}

1. Jamal, M.; Hasan, M.; Mathewson, A.; Razeeb, K. M. Biosens. Bioelectron. 2013, 40, 213-218. doi:10.1016/j.bios.2012.07.024

2. Wang, W.; Yi, C.; Fan, K. Trans. Nonferrous Met. Soc. China 2013, 23, 3353-3361. doi:10.1016/S1003-6326(13)62875-7

3. Samardak, A. S.; Sukovatitsina, E. V.; Ognev, A. V.; Chebotkevich, L. A.; Mahmoodi, R.; Hosseini, M. G.; Peighambari, S. M.; Nasirpouri, F. Phys. Procedia 2011, 22, 549-556. doi:10.1016/j.phpro.2011.11.085

4. Golovach, G. P.; Popov, M. A.; Roussigné, Y.; Stashkevich, A. A.; Zavislyak, I. V. J. Magn. Magn. Mater. 2015, 382, 252-264. doi:10.1016/j.jmmm.2015.01.077

5. Tannous, C.; Gieraltowski, J. Appl. Phys. Lett. 2014, 104, 032403. doi:10.1063/1.4862924

6. Li, X.; Wang, C.; Han, X. Mater. Chem. Phys. 2014, 147, 403-409. doi:10.1016/j.matchemphys.2014.05.002 
7. Dolgiy, A. L.; Redko, S. V.; Komissarov, I.; Bondarenko, V. P.; Yanushkevich, K. I.; Prischepa, S. L. Thin Solid Films 2013, 543 , 133-137. doi:10.1016/j.tsf.2013.01.049

8. Hamrakulov, B.; Kim, I.-S.; Lee, M. G.; Park, B. H. Trans. Nonferrous Met. Soc. China 2009, 19, S83-S87. doi:10.1016/S1003-6326(10)60250-6

9. Ohgai, T.; Enculescu, I.; Zet, C.; Westerberg, L.; Hjort, K.; Spohr, R.; Neumann, R. J. Appl. Electrochem. 2006, 36, 1157-1162. doi:10.1007/s10800-006-9200-5

10. Gu, Q.; Jin, H.; Dai, K. J. Phys. D: Appl. Phys. 2009, 42, 015303. doi:10.1088/0022-3727/42/1/015303

11. Jung, Y. S.; Lee, J. H.; Lee, J. Y.; Ross, C. A. Nano Lett. 2010, 10, 3722-3726. doi:10.1021/nl1023518

12. Kong, Y. Y.; Pang, S. C.; Chin, S. F. Mater. Lett. 2015, 142, 1-3. doi:10.1016/j.matlet.2014.11.140

13. Wang, F.; Zhang, Z.; Chang, Z. Mater. Lett. 2002, 55, 27-29. doi:10.1016/S0167-577X(01)00613-9

14. Wang, F.; Gu, H.; Zhang, Z. Mater. Res. Bull. 2003, 38, 347-351. doi:10.1016/S0025-5408(02)01023-1

15. Li, X.; Han, C. J. Cryst. Growth 2007, 309, 60-64. doi:10.1016/j.jcrysgro.2007.09.015

16. Hu, H.; Sugawara, K. Chem. Phys. Lett. 2009, 477, 184-188. doi:10.1016/j.cplett.2009.06.085

17. Soumare, Y.; Dakhlaoui-Omrani, A.; Schoenstein, F.; Mercone, S.; Viau, G.; Jouini, N. Solid State Commun. 2011, 151, 284-288. doi:10.1016/j.ssc.2010.12.004

18. Liu, P.; Li, Z.; Zhao, B.; Yadian, B.; Zhang, Y. Mater. Lett. 2009, 63, 1650-1652. doi:10.1016/j.matlet.2009.04.031

19. Kawamori, M.; Yagi, S.; Matsubara, E. J. Electrochem. Soc. 2011, 158, E79. doi:10.1149/1.3596703

20. Balela, M. D. L.; Yagi, S.; Matsubara, E. Electrochem. Solid-State Lett. 2011, 14, D68. doi:10.1149/1.3568829

21. Balela, M. D. L.; Yagi, S.; Matsubara, E. J. Electrochem. Soc. 2011, 158, D210. doi:10.1149/1.3545065

22. Zhang, M.; Deng, J.; Zhang, M.; Li, W. Chin. J. Catal. 2009, 30 , 447-452. doi:10.1016/S1872-2067(08)60111-4

23. Li, M.; Xie, K.; Wu, Y.; Yang, Q.; Liao, L. Mater. Lett. 2013, 111, 185-187. doi:10.1016/j.matlet.2013.08.088

24. Wang, H.; Li, X.; Li, M.; Xie, K.; Liao, L. Beilstein J. Nanotechnol. 2015, 6, 1268-1271. doi:10.3762/bjnano.6.130

25. Leslie-Pelecky, D. L.; Rieke, R. D. Chem. Mater. 1996, 8, 1770-1783. doi:10.1021/cm960077f

26. Marder, M. Phys. Rev. A 1987, 36, 858-874. doi:10.1103/PhysRevA.36.858

27. Voorhees, P. W. Annu. Rev. Mater. Sci. 1992, 22, 197-215. doi:10.1146/annurev.ms.22.080192.001213

28. Voorhees, P. W. J. Stat. Phys. 1985, 38, 231-252. doi:10.1007/BF01017860

29. Cao, G.; Wang, Y. Nanostructures and Nanomaterials: Synthesis, Properties, and Applications.; Higher Education Press: Beijing, China, 2012.

30. Choi, J.-Y.; Lee, Y.-K.; Yoon, S.-M.; Lee, H. C.; Kim, B.-K.; Kim, J. M.; Kim, K.-M.; Lee, J.-H. J. Am. Ceram. Soc. 2005, 88, 3020-3023. doi:10.1111/j.1551-2916.2005.00582.x

31. Israelachivili, J. N. Intermolucular and Surface Forces; Science Press: Beijing, China, 2014.

32. Srikanth, S.; Valery, B. Appl. Phys. Lett. 2005, 87, 162511. doi:10.1063/1.2105988

33. Jia, P.; Gao, L. J. Phys. Chem. C 2008, 112, 666-671. doi:10.1021/jp0763477
34. Sheparovych, R.; Sahoo, Y.; Motornov, M.; Wang, S.; Luo, H.; Prasad, P. N.; Sokolov, I.; Minko, S. Chem. Mater. 2006, 18, 591-593. doi:10.1021/cm051274u

35. Abu-Much, R.; Gedanken, A. Chem. - Eur. J. 2008, 14, 10115-10122. doi:10.1002/chem.200801469

\section{License and Terms}

This is an Open Access article under the terms of the Creative Commons Attribution License

(http://creativecommons.org/licenses/by/2.0), which permits unrestricted use, distribution, and reproduction in any medium, provided the original work is properly cited.

The license is subject to the Beilstein Journal of Nanotechnology terms and conditions:

(http://www.beilstein-journals.org/bjnano)

The definitive version of this article is the electronic one which can be found at: doi:10.3762/bjnano.6.217 